\title{
OPTIMASI FORMULA FAST DISINTEGRATING TABLET DOMPERIDONE DENGAN AMILUM BIJI ALPUKAT (Persea americana Mill.) SEBAGAI SUPERDISINTEGRANT
}

\author{
Khusnul Milatul Khasanah ${ }^{1}$, Wirasti*2 ${ }^{2}$,Dwi Bagus Pambudi ${ }^{3}$, ST. Rahmatullah ${ }^{4}$ \\ 1,*2,3,4 Program Studi Sarjana Farmasi, Fakultas Ilmu Kesehatan, Universitas Muhammadiyah \\ Pekajangan Pekalongan \\ e-mail: ${ }^{1}$ khusnulmila99@gmail.com, ${ }^{* 2}$ wirasti.kharis@gmail.com, ${ }^{3}$ dwibagus589@umpp.ac.id, \\ 4amma88.an@gmail.com
}

\begin{abstract}
ABSTRAK
Biji alpukat (Persea americana Mill.) dapat dikembangkan menjadi amilum biji alpukat (Persea americana Mill.) yang dapat digunakan menjadi bahan eksipien formulasi sediaan farmasi. Akan tetapi informasi terkait manfaatnya dalam tablet masih sangat terbatas penggunaannya, sehingga industri farmasi masih jarang menggunakan amilum biji alpukat sebagai alternatif pengganti bahan eksipien dari bahan sintetis superdisintegrant pada fast disintegrating tablet (FDT). Telah dibuat sediaan fast disintegrating tablet dengan variasi konsentrasi amilum biji alpukat (5\%, 10\% dan 15\%) dan pembanding Sodium Starch Glycolate (SSG) konsentrasi 5\%. Data yang didapat dianalisis secara statistik menggunakan uji one way ANOVA dan dilanjutkan ke uji tukey (Honestly Significant Difference) HSD. Hasil menunjukkan bahwa variasi konsentrasi amilum biji alpukat terdapat pengaruh pada sifat fisik granul dan sifat fisik tablet, formula III dengan konsentrasi 15\% memiliki kriteria yang paling baik sebagai superdisintegrant pada tablet terdisintegrasi cepat. Perlu dilakukan modifikasi lanjutan amilum biji alpukat agar dapat digunakan sebagai superdisintegrant yang lebih efektif dalam formulasi fast disintegrating tablet pada penelitian selanjutnya.
\end{abstract}

Kata kunci: Biji alpukat, Amilum, Superdisintegrant, Fast Disintegration Tablet

\begin{abstract}
Avocado seeds (Persea americana Mill.) can be developed into avocado seed starch (Persea americana Mill.) which can be used as excipients in pharmaceutical formulations. However, information related to its benefits in tablets is still very limited, so the pharmaceutical industry still rarely uses avocado seed starch as an alternative to substitute excipients from synthetic superdisintegrants in fast disintegrating tablets (FDT). Fast disintegrating tablet preparations have been made with various concentrations of avocado seed starch (5\%, 10\% and 15\%) and a 5\% concentration of Sodium Starch Glycolate (SSG). The data obtained were analyzed statistically using the one way ANOVA test and continued to the Tukey (Honestly Significant Difference) HSD test. The results showed that variations in the concentration of avocado seed starch had an effect on the physical properties of the granules and the physical properties of tablets, formula III with a concentration of $15 \%$ had the best criteria as a superdisintegrant in rapidly disintegrating tablets. It is necessary to further modify the avocado seed starch so that it can be used as a more effective superdisintegrant in the formulation of fast disintegrating tablets in future studies.
\end{abstract}

Keywords: Avocado seeds, Starch, Superdisintegrant, Fast Disintegration Tablets

\section{PENDAHULUAN}

Salah satu hasil tanaman yang memiliki potensial untuk dikembangkan adalah buah alpukat (Persea americana Mill.). Kebanyakan masyarakat hanya menggunakan dagingnya dan menyisakan biji serta kulitnya terbuang dengan percuma, sehingga menjadi salah satu limbah dan menyebabkan pencemaran. Padahal di dalam biji alpukat (Persea americana Mill.) mengandung amilosa yang memiliki kemampuan amilum sebagai bahan penghancur sekitar 32,5\% [1]. Menurut [2], amilosa memiliki sifat yang tidak melarut dalam air dingin. Namun, bisa menyerap 
air dalam jumlah besar dan menyebar sehingga dapat digunakan sebagai penghancur tablet. Penelitian sebelumnya oleh Aeni [3] menyatakan bahwa amilum biji alpukat (Persea americana Mill.) pregelatinasi dapat digunakan sebagai eksipien kempa langsung sebagai bahan penghancur dan menghasilkan tablet yang baik pada konsentrasi optimum amilum biji alpukat yaitu $10 \%$.

Seiring berkembangnya terknologi dan dorongan inovasi yang tinggi, biji alpukat (Persea americana Mill.) dapat dikembangkan menjadi amilum biji alpukat (Persea americana Mill.) yang dapat digunakan menjadi bahan eksipien formulasi sediaan farmasi. Akan tetapi informasi terkait manfaatnya dalam tablet masih sangat terbatas penggunaannya, sehingga industri farmasi masih jarang menggunakan amilum biji alpukat sebagai alternatif pengganti bahan eksipien dari bahan sintetis superdisintegrant pada fast disintegrating tablet (FDT). Padahal amilum biji alpukat memiliki kelembapan 0\% yang dapat mempengaruhi hasil sifat fisika-kimia baik untuk granul maupun tablet serta dapat menghambat tumbuhnya mikrobiologi dari sediaan farmasi yang dibuat.

Domperidone $10 \mathrm{mg}$ dipilih sebagai zat aktif karena memiliki efek terapi sebagai antiemetik yang banyak digunakan untuk pasien, sehingga cocok digunakan untuk penelitian dengan dibuat sediaan tablet dengan waktu hancur yang cepat [4]. Selain itu pemilihan domperidone 10 mg dibuat sediaan fast disintegration tablet (FDT) memiliki keunggulan untuk pasien yang susah dalam mengkonsumsi tablet dan dosis tablet yang lebih tepat dibandingkan dengan sediaan sirup. Metode yang digunakan dalam pembuatan sediaan ini dengan metode cetak langsung, metode ini dipilih karena bahan-bahan yang akan dibuat tablet memiliki sifat alir yang baik dan dapat membantu dalam proses pemecahan tablet secara cepat setelah kontak dengan cairan di mulut. Sehingga lebih efektif apabila dilakukan pembuatan tablet dengan menggunakan metode cetak langsung [5].

Tujuan penelitian ini mengembangkan suatu formulasi FDT Domperidone $10 \mathrm{mg}$ dengan menggunakan amilum biji alpukat (Persea americana Mill.) sebagai superdisintegrant yang dapat memenuhi persyaratan tablet yang baik serta mengetahui konsentrasi yang optimum dari penggunaan amilum biji alpukat (Persea americana Mill.) sebagai superdisintegrant.

\section{METODE PENELITIAN}

\subsection{Alat dan Bahan}

Alat yang digunakan adalah pisau, blender, oven, neraca analitik (ohaus), toples, baskom, ayakan granul (nomor 40 dan 100), oven listrik, corong kaca, mesin tablet single punch, hardness tester (lokal), friability tester (goaming), stopwatch, disintegration tester (goaming), tapdensiti meter (lokal), moistured balance, pinset, seperangkat alat titrasi, jangka sorong (lokal), alat uji waktu alir (lokal), kertas saring, cawan petri dan alat-alat gelas (pyrex) lainnya.

Bahan yang digunakan yaitu domperidone $10 \mathrm{mg}$, biji alpukat, manitol, magnesium stearat, talkum, aquadest, natrium metabisulfit $\left(\mathrm{Na}_{2} \mathrm{~S}_{2} \mathrm{O}_{5}\right)$, pereaksi iodium, etanol $70 \%$, sodium starch glycolate, natrium hidroksida $(\mathrm{NaOH})$ dan penolftalein.

Tabel I. Rancangan Formulasi Fast disintegrating tablet

\begin{tabular}{cccccc}
\hline \multirow{2}{*}{ Bahan } & Keterangan & \multicolumn{3}{c}{ Formulasi } & \multirow{2}{*}{ Pembanding } \\
\cline { 3 - 5 } & & $\mathrm{F} 1$ & $\mathrm{~F} 2$ & $\mathrm{~F} 3$ & $10 \mathrm{mg}$ \\
Domperidone & zat aktif & $10 \mathrm{mg}$ & $10 \mathrm{mg}$ & $10 \mathrm{mg}$ & q.s $(100$ \\
$\begin{array}{c}\text { Avicel PH } \\
102\end{array}$ & Pengisi & q.s $(100 \%)$ & q.s $(100 \%)$ & $\%)$ & q.s $(100 \%)$ \\
$\begin{array}{c}\text { Amilum biji } \\
\text { alpukat }\end{array}$ & superdisintegrant & $5 \%$ & $10 \%$ & $15 \%$ & - \\
Talk $(2 \%)$ & Pelincir & $2 \%$ & $2 \%$ & $2 \%$ & $2 \%$ \\
Magnesium & Pelicin & $1 \%$ & $1 \%$ & $1 \%$ & $1 \%$
\end{tabular}




\begin{tabular}{|c|c|c|c|c|c|}
\hline $\begin{array}{c}\text { Manitol } \\
(20 \%)\end{array}$ & pengisi & $20 \%$ & $20 \%$ & $20 \%$ & $20 \%$ \\
\hline $\begin{array}{c}\text { Sodium Starch } \\
\text { Glycolate }\end{array}$ & superdisintegrant & - & - & - & $5 \%$ \\
\hline $\begin{array}{r}\text { Bol } \\
\text { Jum }\end{array}$ & $\begin{array}{l}\text { t tablet } \\
\text { ah tablet }\end{array}$ & $\begin{array}{c}200 \mathrm{mg} \\
100\end{array}$ & $\begin{array}{c}200 \mathrm{mg} \\
100\end{array}$ & $\begin{array}{c}200 \mathrm{mg} \\
100\end{array}$ & $\begin{array}{c}200 \mathrm{mg} \\
100\end{array}$ \\
\hline
\end{tabular}

Keterangan : 1 batch $=100$ tablet $@$ tablet $\mathrm{fdt}=200 \mathrm{mg}$

\subsection{Jalannya Penelitian}

\subsubsection{Pembuatan amilum biji alpukat (Persea americana Mill.)}

Dikupas kulit amilum biji alpukat (Persea americana Mill.) dan dicuci bersih, dipotongpotong biji apukat untuk memperkecil ukurannya. kemudian dihaluskan menggunakan blender dan ditambahkan air dengan perbandingan 1:1 (1 liter air untuk $1 \mathrm{~kg}$ amilum biji alpukat) campuran ini disebut bubur biji. Ditambahkan air kedalam bubur biji kemudian disaring, filtrat dibiarkan mengendap selama $24 \mathrm{jam}$. Air bening yang terbentuk diatasnya dibuang dan hasil endapan dicuci dengan air bersih yang kemudian diendapkan lagi sebanyak 3 kali. dilakukan penambahan larutan pemutih natrium metabisulfit sebanyak 6 gram yang dilarutkan dalam 30 liter air suling kemudian dibilas dengan air bersih dan diendapkan kembali. Endapan yang diperoleh dikeringkan dalam oven lalu diayak menggunakan ayakan mesh nomer 100 [6]. Dihitung randemen amilum yang dihasilkan dan dilakukan evaluasi amuilum berdasarkan Farmakope Indonesia Edisi VI.

\subsubsection{Pembuatan Fast Disintegrating Tablet Secara Cetak Langsung}

Domperdone $10 \mathrm{mg}$ sebagai zat aktif mixing terlebih dahulu selama 3 menit, ditambahkan avicel PH 102 setengahnya kedalam domperidone $10 \mathrm{mg}$ dilakukan mixing selama 5 menit. Dimasukkan superdisintergant amilum biji alpukat dimixing selama 5 menit. Selanjutnya dimasukkan manitol dan sisa avicel PH 102 mixing selama 10 menit, kemudian ditambahkan magnesium stearat dan talkum dimixing selama 3 menit. Pada serbuk granul dilakukan evaluasi granul, apabila memenuhi syarat yang telah ditentukan maka serbuk granul dilanjutkan dengan pencetakan tablet menggunakan alat pencetak tablet single punch.

\subsubsection{Evaluasi sifat fisik tablet \\ Uji Keseragaman Bobot Tablet}

Diambil sebanyak 20 tablet yang telah dicetak, lalu timbang satu persatu tablet dengan timbangan analitik dan dihitung bobot rata-rata tablet [7].

\section{Uji Dimensi / Keseragaman Ukuran Tablet}

Dilakukan dengan mengambil 5 tablet yang telah dicetak, kemudian masing - masing tablet diukur diameter dan tebalnya yang dilakukan dengan alat jangka sorong [5].

\section{Uji Kekerasan Tablet}

Disiapkan alat hardness tester dan 5 tablet yang telah dicetak, kemudian di"nol" kan skala pada alat. Letakkan tablet pada alat dengan posisi melintang dan putar alat hingga tablet pecah, selanjutnya baca nilai yang tertera pada skala alat [8].

\section{Uji Kerapuhan Tablet}

Diambil 20 tablet yang telah dicetak, selanjutnya satu persatu tablet dibebas debukan dan ditimbang secara bersamaan serta catat hasil bobot tabletnya sebagai bobot awal $\left(\mathrm{W}_{0}\right)$. Lalu dimasukkan tablet kedalam alat Friability Tester dan nyalakan alat selama 4 menit menggunakan stopwatch. Selanjutnya masing - masing tablet yang telah dikeluarkan dari alat Friability Tester dibebas debukan dan ditimbang kembali. Catat hasil bobot 20 tablet tersebut sebagai bobot akhir $\left(\mathrm{W}_{1}\right)$ dan ditentukan hasil prosentase kerapuhan tablet [5]. 


\section{Uji Waktu Pembasahan Tablet}

Dimasukkan selembar kertas saring kedalam cawan petri berukuran diameter $50 \mathrm{~cm}$ yang berisi aquadest sebanyak $10 \mathrm{~mL}$ dan diberi indikator pewarna, dimasukkan dimasukkan kedalam cawan petri dan catat waktu yang diperlukan larutan pewarna untuk membasahi seluruh permukaan tablet [9].

\section{Uji Waktu Hancur Tablet}

Dimasukkan $10 \mathrm{ml}$ aquadest kedalam cawan petri berdiameter $50 \mathrm{~cm}$ yang sudah diberi selembar kertas saring. Kemudian dimasukkan tablet kedalam cawan dan catat waktu yang diperlukan 1 tablet untuk terdisintegrasi sampai tidak ada sisa yang tertinggal, kemudian dihitung rata-ratanya [9].

\subsection{Analisis Data}

Data yang telah diperoleh dari hasil pengujian sifat fisik granul dan tablet fast disintergation tablet (FDT) dibandingkan dengan persyaratan teoritis pada buku Farmakope Indonesia dan Literatur lainnya untuk persyaratan fast disintergation tablet (FDT) yang baik kemudian dilanjutkan dengan analisis data menggunakan ANOVA one way dan Uji Tukey.

\section{HASIL DAN PEMBAHASAN}

Tabel II. Hasil Uji Organoleptis Amilum Biji Alpukat

\begin{tabular}{ccccc}
\hline Organoleptis & F I & F II & FIII & Pembanding \\
\hline Bentuk & Serbuk halus & Serbuk halus & Serbuk halus & Serbuk \\
Warna & Kecoklatan & Kecoklatan & Kecoklatan & Putih \\
Bau & Khas lemah & Khas lemah & Khas lemah & Tidak berbau \\
\hline \multicolumn{2}{l}{ Randemen amilum biji alpukat yang diperoleh sebesar $2,767 \%$, dilihat dari tabel 2 warna }
\end{tabular}
dihasilkan amilum adalah kecoklatan dikarenakan adanya faktor reaksi browning saat proses perendaman dan penghancuran biji alpukat yang tidak bisa dihindari padahal sudah dilakukan pencegahan dengan pemberian larutan natrium metabisulfit. Hal ini diperngaruhi oleh faktor adanya kontak enzim polifenol oksidase dengan senyawa fenolik dopamin dari biji alpukat, adanya oksigen yang dihasilkan dari proses pengirisan dan penghancuran menyebabkan reaksi browning [7].

Tabel III. Hasil Evaluasi Amilum Biji Alpukat

\begin{tabular}{|c|c|c|c|}
\hline $\begin{array}{c}\text { Pengujian } \\
\text { Amilum }\end{array}$ & Persyaratan Amilum & Hasil Uji Amilum & Keterangan \\
\hline Kelarutan & $\begin{array}{c}\text { Praktis tidak larut } \\
\text { dalam air dingin dan } \\
\text { etanol }\end{array}$ & $\begin{array}{l}\text { Praktis tidak larut } \\
\text { dalam air dingin } \\
\text { dan etanol }\end{array}$ & $\begin{array}{l}\text { Memenuhi } \\
\text { persyaratan }\end{array}$ \\
\hline $\begin{array}{l}\text { Penetapan } \\
\text { keasaman }\end{array}$ & $\begin{array}{c}\text { Penggunaan larutan } \\
\mathrm{NaOH} 0,1 \mathrm{~N} \text { tidak } \\
\text { lebih dari } 2,00 \mathrm{ml} \text {. }\end{array}$ & $\begin{array}{c}\text { Penggunaan larutan } \\
\mathrm{NaOH} 0,1 \mathrm{~N} \\
\text { sebanyak } 0,68 \mathrm{ml} \pm \\
0,09 .\end{array}$ & $\begin{array}{l}\text { Memenuhi } \\
\text { persyaratan }\end{array}$ \\
\hline Identifikasi & $\begin{array}{l}\text { Terbentuk warna biru } \\
\text { tua }\end{array}$ & $\begin{array}{c}\text { Terbentuk warna } \\
\text { biru tua }\end{array}$ & $\begin{array}{l}\text { Memenuhi } \\
\text { persyaratan }\end{array}$ \\
\hline Kadar air & Kurang dari $15 \%$ & Kadar air $0,30 \%$ & $\begin{array}{l}\text { Memenuhi } \\
\text { persyaratan }\end{array}$ \\
\hline
\end{tabular}

Amilum biji aplukat terdapat kandungan amilosa sebanyak 32,5\% dan amilopektin $67,5 \%$. Amilopektin memiliki karakteristik yang tidak larut dalam air dan pelarut polar, sehingga 
pada uji kelarutan amilum di dalam dua pelarut yaitu air dingin dan etanol tidak terlarut dan terlihat adanya endapan yang terbentuk.

Uji identifikasi amilum dilakukan bertujuan untuk memastikan bahwa bahan yang akan digunakan adalah amilum, Berdasarkan literaturnya akan terbentuk reaksi positif jika menghasilkan warna biru tua sesuai dengan teori pada Farmakope Indonesia Edisi VI. Hasil dari uji identifikasi amilum yang telah dilakukan menghasilkan warna biru tua keunguan, sehingga hasil tersebut sesuai dengan teorinya yang mengandung amilum.

Nilai keasaman amilum yang diperoleh memenuhi standar mutu amilum menurut Farmakope Indonesia Edisi VI yaitu tidak lebih dari 2,00 ml larutan 0,1 N. Hasil ini dapat meminimalkan adanya pembentukan asam-asam organik yang dihasilkan dari aktivitas antimikroba selama proses perendaman hingga pengeringan amilum biji alpukat.

Tujuan uji kadar air untuk menghindari kelembapan amilum yang dapat memicu tumbuhnya mikroba, karena kadar air yang tinggi dapat memicu reaksi enzimastik maupun pertumbuhan mikroba sehingga dapat terjadi pembusukan sehingga merusak mutu amilum [7]. Syarat kadar air pada amilum yaitu tidak boleh lebih dari 15\% di dalam Farmakope Indonesia Edisi VI, sedangkan hasil dari penelitian yang dilakukan memiliki kadar air sebesar 0,30\% sehingga memenuhi persayaratannya.

Tablel IV. Hasil Evaluasi Granul

\begin{tabular}{|c|c|c|c|}
\hline Uji granul & Persyaratan Amilum & Hasil Uji Amilum & Keterangan \\
\hline Laju alir & $\begin{array}{c}\text { Serbuk granul dapat } \\
\text { mengalir dengan bebas } \\
\text { apabila laju alir serbuk } \\
\text { granul > } 10 \text { gram/detik }\end{array}$ & $\begin{array}{c}\text { Serbuk granul } \\
\text { memiliki laju alir } \\
>10 \text { gram/detik, } \\
\text { granul mudah } \\
\text { mengalir bebas }\end{array}$ & $\begin{array}{l}\text { Granul mudah } \\
\text { mengalir bebas }\end{array}$ \\
\hline Sudut diam & $\begin{array}{l}\text { Sudut diam } \leq 30^{\circ} \\
\text { maka granul memiliki } \\
\text { aliran yang baik dan } \\
\text { mudah mengalir bebas }\end{array}$ & $\begin{array}{l}\text { Memperoleh nilai } \\
\text { sudut diam } \leq 30^{\circ} \\
\text { granul mudah } \\
\text { mengalir bebas }\end{array}$ & $\begin{array}{c}\text { Granul } \\
\text { memiliki aliran } \\
\text { yang baik dan } \\
\text { mudah } \\
\text { mengalir bebas }\end{array}$ \\
\hline $\begin{array}{c}\text { Indeks } \\
\text { kompresibilitas }\end{array}$ & $\begin{array}{l}\text { Indeks kompresibilitas } \\
<20 \%\end{array}$ & $\begin{array}{c}\text { Memperoleh indeks } \\
\text { kompresibilitas }< \\
20 \%\end{array}$ & $\begin{array}{l}\text { Memiliki siifat } \\
\text { alir granul yang } \\
\text { baik }\end{array}$ \\
\hline
\end{tabular}

\section{Uji Keseragaman Bobot Tablet}

Pada table 5 terlihat pada semua formula memiliki nilai rata-rata prosentase yang sama, hal ini menandakan bahwa saat proses pencetakan tablet pada laju alir, sudut diam dan indeks kompresibilitas menghasilkan nailai yang baik pada formula. Hasil dari uji keseragaman bobot semua formula memenuhi persyaratan karena dengan bobot tablet $<200 \mathrm{mg}$ tidak ada tablet yang menyimpang dari kolom A $(7,5 \%)$ dan tidak ada satupun tablet yang menyimpang dari kolom $\mathrm{B}$ (15\%) sesuai persyaratan pada Farmakope Indonesia Edisi VI [7].

Table V. Hasil Uji Keseragaman Bobot

\begin{tabular}{|c|c|c|c|c|c|c|}
\hline \multirow{2}{*}{ Tablet } & \multirow{2}{*}{$\begin{array}{c}\text { Formula } \\
\text { I } \\
\%\end{array}$} & \multirow{2}{*}{$\begin{array}{c}\text { Formula } \\
\text { II } \\
\%\end{array}$} & \multirow{2}{*}{$\begin{array}{c}\text { Formula } \\
\text { III } \\
\%\end{array}$} & \multirow{2}{*}{$\begin{array}{c}\text { Pembanding } \\
\%\end{array}$} & \multicolumn{2}{|c|}{ Bobot penyimpangan } \\
\hline & & & & & $\mathrm{A}(\mathbf{7 , 5 \% )}$ & B (15\%) \\
\hline$\overline{\mathrm{X}}$ & 0,01 & 0,01 & 0,01 & 0,01 & $\checkmark$ & $\checkmark$ \\
\hline SD & 0,01 & 0,006 & 0,01 & 0,01 & $\checkmark$ & $\checkmark$ \\
\hline
\end{tabular}




\section{Uji Keseragaman Ukuran Tablet}

Pada table 6. Terlihat bahwa Formula I sampai Formula Pembanding dinyatakan seragam ukurannya, karena telah memenuhi persyaratan keseragaman ukuran menurut Farmakope Indonesia Edisi VI yang menyatakan bahwa keseragaman ukuran menurut Farmakope Indonesia Edisi VI yaitu diameter tablet tidak boleh lebih dari 3 kali tebal tablet dan tidak boleh kurang dari satu sepertiga tebal tablet. Factor yang mempengaruhi keseragaman ukuran yaitu laju alir granul omogenitas saat pencampuran bahan serta kestabilan punch pencetakan [7].

Table VI. Hasil Uji Keseragaman Bobot

\begin{tabular}{ccccccccc}
\hline & \multicolumn{2}{c}{ Formula I } & \multicolumn{2}{c}{ Formula II } & \multicolumn{2}{c}{ Formula III } & \multicolumn{2}{c}{ Pembanding } \\
\cline { 2 - 9 } Tablet ke- & $\begin{array}{c}\mathbf{D} \\
(\mathbf{m m})\end{array}$ & $\begin{array}{c}\mathbf{T} \\
(\mathbf{m m})\end{array}$ & $\begin{array}{c}\mathbf{D} \\
(\mathbf{m m})\end{array}$ & $\begin{array}{c}\mathbf{T} \\
(\mathbf{m m})\end{array}$ & $\begin{array}{c}\mathbf{D} \\
(\mathbf{m m})\end{array}$ & $\begin{array}{c}\mathbf{T} \\
(\mathbf{m m})\end{array}$ & $\begin{array}{c}\mathbf{D} \\
(\mathbf{m m})\end{array}$ & $\begin{array}{c}\mathbf{T} \\
(\mathbf{m m})\end{array}$ \\
\hline$\overline{\mathrm{X}}$ & 7,86 & 3,47 & 7,87 & 3,27 & 7,89 & 3,42 & 7,87 & 3,44 \\
SD & 0,09 & 0,07 & 0,05 & 0,07 & 0,03 & 0,08 & 0,05 & 0,09 \\
Persyaratan & 10,41 & 1,15 & 9,81 & 1,09 & 10,26 & 1,14 & 10,32 & 1,15 \\
\hline
\end{tabular}

\section{Uji Kekerasan Tablet}

Kekuatan tablet ditentukan dengan cara mengukur kekerasan tablet, syarat kekerasan fast disintegrating tablet adalah 1-3 Kp [10]. Pada F I kekerasannya lebih dari $3 \mathrm{Kp}$, hal ini dapat berakibat menurunnya waktu disintegrasi tablet [5]. Tidak seragamnya kekerasan pada formula disebabkan karena tekanan yang diberikan saat pencetakan tidak sama sehingga menyebabkan adanya perbedaan kekerasan pada sediaan.

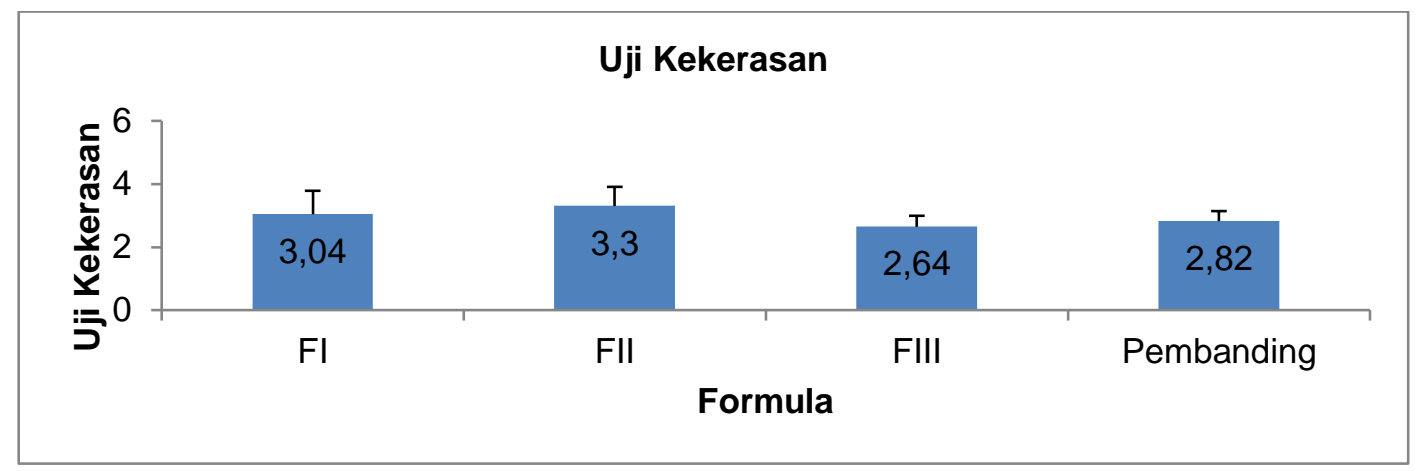

\section{Gambar 1. Diagram Hasil Uji Statistik Kekerasan Tablet}

\section{Uji Kerapuhan Tablet}

Penentuan kekuatan tablet salah satunya uji kerapuhan tablet yang bertujuan untuk mengetahui bahwa tablet memiliki kekuatan atas kerapuhan agar dapat bertahan terhadap berbagai guncangan mekanik pada saat pembuatan, pengepakan, distribusi dan penyimpanan [5]. Pada gambar 1 terlihat bahwa kerapuhan F II lebih tinggi dibandingkan dengan lainnya, tetapi masih dalam rentang persyaratan uji kerapuhan tablet. Factor yang mempengaruhi kerpauhan tablet karena di dalam formula tidak menggunakan bahan tambahan pengikat, sehingga daya ikat antar partikel kecil dan sangat rendah. 


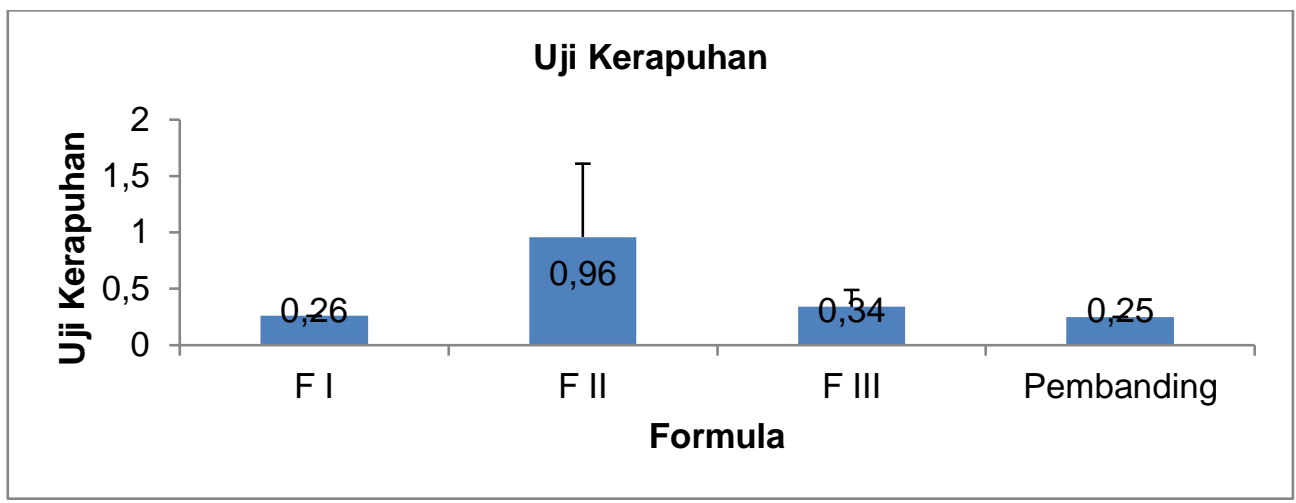

Gambar 2. Diagram Hasil Uji Statistik Kerapuhan Tablet

\section{Uji Waktu Pembasahan Tablet}

Pada gambar 2 terlihat bahwa F III memiliki waktu pembasahan yang lebih singkat dibandingkan dengan F I dan F II, dikarenakan pada FIII mengandung konsentrasi amilum biji alpukat yang lebih banyak. Amilum biji alpukat memiliki afinitas daya serap air yang lebih tinggi sehingga dapat mengembang lebih cepat dan dapat mengancurkan matriks tablet. Kemampuan menyerap air yang tinggi dari medium dipastikan lebih kuat akibatnya waktu pembasahan menjadi lebih cepat [10].

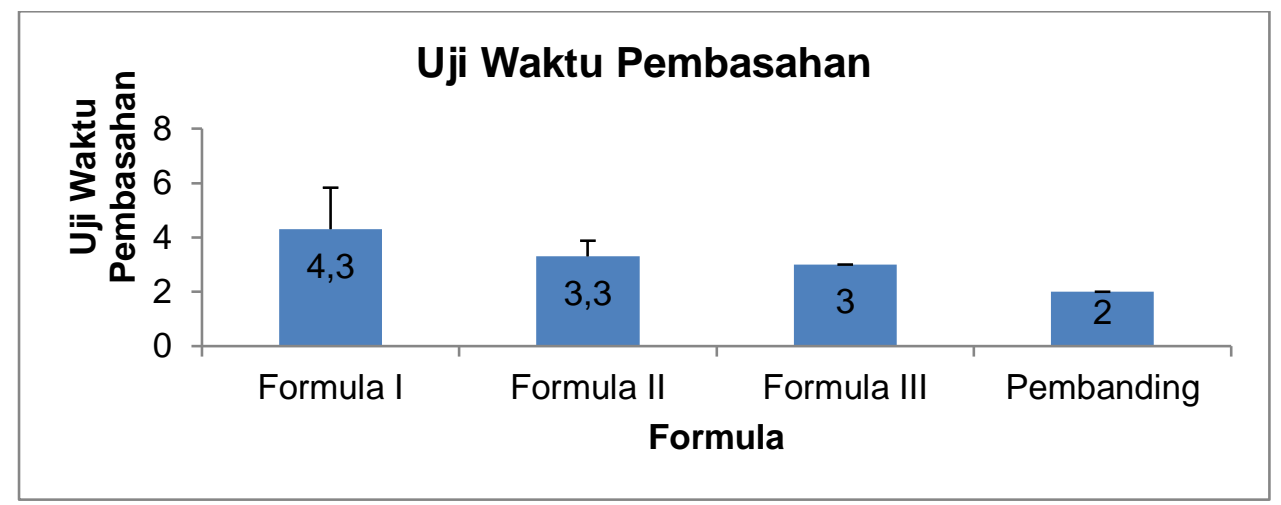

Gambar 3. Diagram Hasil Uji Statistik Waktu Pembasahan

\section{Uji Waktu Hancur Tablet}

Waktu disintegrasi adalah parameter penting pada sediaan fast disintegrating tablet untuk mengetahui seberapa lama waktu hancur tablet setelah kontak dengan cairan di dalam mulut. Modifikais fast disintegrating tablet dilakukan dengan membuat suatu kondisi yang hampir sama dengan keadaan rongga mulut manusia.

Persyaratan waktu hancur fast disintegrating tablet menurut Pharmacope European adalah kurang dari 3 menit, pada gambar 3 terlihat F III memiliki waktu disintegrasi yang lebih singkat dibandingkan dengan F I dan F II, dikarenakan pada FIII mengandung konsentrasi amilum biji alpukat yang lebih banyak. Factor lain karena dibantu dengan penggunaan Avicel PH 102 selain berfungsi sebagai pengisi juga berfungsi sebagai disintegrant sehingga waktu disintegrasi lebih maksimal.

Pada gambar 3 terlihat bahwa F I memiliki waktu disintegrasi lebih lama karena menggunakan konsentrasi amilum biji alpukat paling rendah. Penggunaan semakin tinggi konsentrasi manitol yang digunakan akan menyebabkan berkurangnya porositas tablet, sehingga proses daya serap air untuk mengembang (swelling) aka jauh berkurang akibatnya disintegrasi 
tablet menjadi lebih lambat [5]. Faktor lain dipengaruhi oleh perbedaa tekanan yang diberikan saat proses pencetakan pada punch, karena alat tersebut digunakan secara bergiliran.

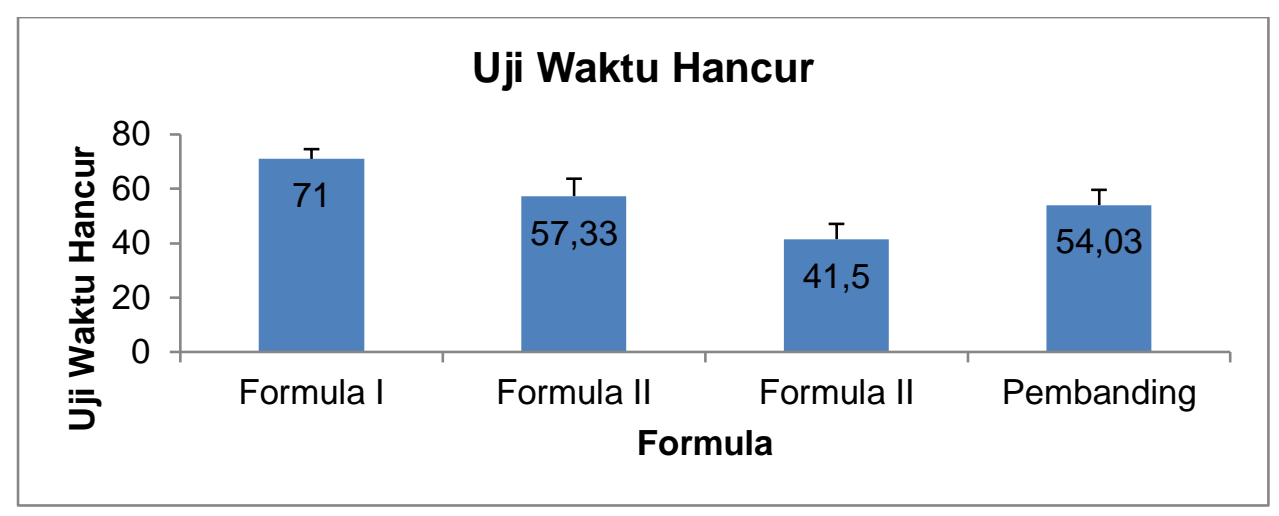

Gambar 3. Diagram Hasil Uji Statistik Waktu Hancur Tablet

\section{KESIMPULAN}

Penggunaan amilum biji alpukat (Persea americana Mill.) dengan variasi konsentrasi $5 \%, 10 \%$ dan $15 \%$ dapat digunakan sebagai bahan superdisintegrant pada fast disintegrating tablet domperidone $10 \mathrm{mg}$. Konsentrasi amilum biji alpukat $15 \%$ menghasilkan sifat fisik granul dan sifat fisik tablet yang baik dan memenuhi persyaratan.

\section{DAFTAR PUSTAKA}

[1] Chel-Guerrero, L., Barbosa-Martín, E., Martínez-Antonio, A., González-Mondragón, E., \& Betancur-Ancona, D, Some PHysicochemical and rheological properties of starch isolated from avocado seeds. International Journal of Biological Macromolecules, Vol. 86, Halaman 302-308, 2016 [Online]. Available https://www.researchgate.net/publication/291375523_Some_physicochemical_and_rheolog ical_properties_of_starch_isolated_from_avocado_seeds.

[2] Ningsi, S., Leboe, D. W., Tahir, K. A., \& Aeni, Q., Studi Kemampuan Pati Biji Alpukat, volume 4, No 3, hal 106-113, 2016, [Online]. Available : http://journal.uinalauddin.ac.id/index.php/jurnal_farmasi/article/view/2233.

[3] Aeni, Q."Studi Kemampuan Pati Biji Alpukat (Persea americana Mill) Pregelatinasi Sebagai Bahan Penghancur Pada Tablet Paracetamol Kempa Langsung", Skripsi, Fakultas Keokteran dan Ilmu Kesehatan, Sarjana Farmasi, Universitas Islam Negeri Alaudin, 37-38, Makassar, 2016.

[4] Shaveta, S., Diksha, C., Puneet, S., \& Upendra, J. K, Short Review on Domperidone tablet. Journal of Applied PHarmaceutical Research, 5(1), 14-19, 2016 [Online]. Available : https://media.neliti.com/media/publications/320070-short-review-on-domperidone-tablet0768124d.pdf.

[5] Lachman, L., Leberman, H. A., dan Kaing, J. L., Teori Dan Praktek Industri Farmasi Edisi II, Vol. II, Edisi 3, 2012, Jakarta : Universitas Indonesia.

[6] Halimah, A.D.N., Istiqomah., dan Rohmah, S.S, Pengolahan Limbah Biji Alpukat Untuk Pembuatan Dodol Pati Sebagai Alternatif Pengobatan Ginjal. Jurnal Ilmiah Mahasiswa vol. 4, no. 1, Apr, 2014 [Online], https://ejournal.undip.ac.id/index.php/jim/article/view/10888.

[7] Departemen Kesehatan Republik Indonesia, Farmakope Indonesia Edisi VI, 2020, Jakarta : Departemen Kesehatan Republik Indonesia. 
[8] Saputro, T. A. D. I, "Optimasi Formula Fast disintegrating tablet Piroksikam Dengan Kombinasi Bahan Halaman Persetujuan Optimasi Formula Fast disintegrating tablet Crospovidone Dan Bahan Pengisi Manitol". Skripsi, Fakultas Farmasi. Sarjana Farmasi. Universitas Muhammadiyah Purwokerto. Purwokerto, 2016

[9] Edityaningrum, C. A., Fauziah, T. S., \& Witasari, H. A, Optimasi Formula Fast disintegrating tablet Ekstrak Daun Belimbing Wuluh ( Averrhoa Bilimbi L .) dengan Kombinasi Superdisintegrant Crospovidone dan Croscarmellose Sodium. Trad. Med. J., 23(1), 62-6, 2018

[10] Prabowo, I, Optimasi Kecepatan Disintegrasi Tablet Terdisintegrasi Cepat ( Fast disintegrating tablet) Domperidon Dengan Superdisintegran Sodium Starch Glycolate, Majalah Ilmu Kefarmasian, Vol. 8(3), Halaman 154-166, 2011 [Online], Available : http://psr.ui.ac.id/index.php/journal/article/view/3480. 